\title{
Promoting Strategies of Interaction Effect between Host and Guest: Based on the Positive Attitude of Community Residents in Ethnic Tourist Areas

\author{
Zeng Yan \\ Culture and Tourism Department Yunnan Open University Kunming 650223
}

Keywords: Host-guest interaction; Residents; Positive attitude; Promoting strategies

\begin{abstract}
In the "interaction between guests and guests" of ethnic tourism, residents' attitude is an important factor that affects the interaction effect. Based on the previous study data on residents in ethnic tourist areas, this paper combines with the different attitude of residents and establishes strategy to promote the interactive effect and get a positive attitude of developing tourism in ethnic tourism from the viewpoint of community groups.
\end{abstract}

\section{Introduction}

Tourism is a direct form of communication between people, and it is also a face-to-face communication between main guests. Ethnic tourism is a tourism activity in which a particular ethnic culture is the main attraction in a specific area. Residents of ethnic tourism destinations cannot simply be considered as people who provide services to tourists in order to satisfy their needs. They make changes to themselves based on what they have learned about "what attracts tourists". There are interesting and complicated interactions and interactions with tourists. The exchange and interaction between the host and guest are constantly changing. As the level of socio-economic development of ethnic tourism destinations and the level of residents' education have increased, residents' consciousness has become awakened and has been placed on safeguarding their own daily lives and protected their privacy. This makes increasingly obvious conflicts, such as the tourism development enterprises only pay attention to the economic benefits of tourism development and ignore the interests of local residents, tourists are in a "strong position" and ignore the benefits of local residents (cultural and economic) that affects the interaction effect between host and guest. As an important influencing factor, the positive attitude of community residents will benefit the creation of a harmonious atmosphere, tourists to obtain a satisfactory tourism experience, the establishment of a good tourist destination image, the benign interaction between residents and tourists and to realize the sustainable development of ethnic tourism destinations. Therefore, this paper takes the residents of Yunnan ethnic tourism sites as the object of investigation and classifies the residents with different cognition of ethnic tourism development. Based on the previous study data on residents in ethnic tourist areas, this paper combines with the different attitude of residents and establishes strategy to promote the interactive effect and get a positive attitude of developing tourism in ethnic tourism from the viewpoint of community groups.

\section{The Principle of Promoting the Positive Attitudes}

"Protection in the Development". To promote the positive attitudes of residents should find a benign development path of ethnic tourism. Ethnic culture is regarded as economic resources and capital in exploiting of ethnic tourism which is the best combining point of economy development and ethnic culture development, is the real driving force of regeneration and creativity of ethnic culture and is the feasible way of sustainable development on the perspective of ethnic culture development.

The target of ethnic tourism development is guaranteeing the rapid and steady development of ethnic tourism and the local community and improving the local social economic development meanwhile protecting the local ethnic culture. "Protection in the development" requires residents' 
initiative facing various challenges in ethnic tourism exploiting and improving awareness which guide them to choose, examines, distinguish, absorb and combine with comprehensive impacts of ethnic tourism development actively and forwardly.

The Government Domination. Development of ethnic tourism destination needs the government policies and measures as dominated situation, which is an effective guarantee for the awaking of the national self-consciousness which is the inner motive power of national culture change. In the process of modernization ethnic culture development depends on the national self-consciousness on a range of issues, such as ethnic culture should be change or unchanged, how should ethnic culture change and where it should be change.

Long term. The impacts of ethnic tourism are a complex system and a developing process in different periods and stage. Therefore adjusting and cultivating residents' positive attitudes are a longterm process and should consistent with local long-term development to plan the feasible strategies and measures in stages.

Based on the Characteristic of Ethnic Culture. In ethnic tourism destination ethnic culture and the unique characteristics are the key of development of ethnic tourism and cause ethnic tourism to be a compound which mixes the foreign culture and local culture, modern culture and traditional culture together. So the different tourist areas should highlight its distinctive characteristics of local traditional culture.

\section{Promoting Strategies of Residents' Positive Attitudes from Ethnic groups}

Based on the above principles and combined with the analysis of the residents' attitudes towards the impact of ethnic tourism destination [1]. The promoting strategies are as follows.

Participation of Ethnic Groups. Community participation is the one of effective ways of sustainable development of ethnic tourism. Before the residents participation they also should to strengthen the self-consciousness to fully understand themselves and the value of national culture and form strong sense of participation. The Resident groups of tourist destinations should be included in the tourism decision and benefit sharing system to coordinate the relationship between stakeholders by fully listening to the views of residents to really become the beneficiaries in ethnic tourism development.

The Promotion Strategies of Different Attitudes of Residents. The residents' attitudes of ethnic tourism are divided into four types: ignoring, rational supporters, optimistic supporters and blind supporter. The rational supporters have expressed cautious support for the status of tourism development and they are not completely satisfied. When the negative effects of the ethnic tourism development gradually know by ethnic groups, the resulting attitudes of residents will be continuous differentiation along with the development of national tourism. This paper illustrates the measures to foster positive attitudes to four kinds of residents in the frontal investigation and expect to give reference to cultivate positive attitudes in different tourist destinations and ethnic groups.

These kinds of people are not concerned about effect of ethnic tourism and keep a mild attitudes to the positive impact of ethnic tourism. While the groups recognize the tourism promote local economic development, but they are indifferent to the others impacts and even basically no understanding on the negative impact of ethnic tourism development. This type of people should be educated on not only understanding the value of ethnic tourism but also actively participating in the development of ethnic tourism to gain opportunities contacting ethnic tourism, working in ethnic tourism industry and to achieve the economic benefits in ethnic tourism.

Such residents continue to support the development of ethnic tourism, but they don't highly concern about tourism impact and not fully understand the negative and positive impact of ethnic tourism. They are low incomes, from long distance to the tourism resources, low educational levels and the low 
dependence degree on ethnic tourism, so they often consider personal livelihood and pay little attention to their living environment, tourism development, social development, etc.

This kind of people should be educated on not only understanding the positive influences of ethnic tourism but also actively participating in the development of ethnic tourism, such as creating some tourism employment opportunities for them because of the long distance from the tourism resources, compensating the subsidies to them for the ethnic tourism investment related costs, applying for government subsidies to reform their own folk house for gaining tourism economic benefits.

The residents are mainly of young, great contact with tourism, feeling more positive impact on ethnic tourism which weakens its negative effect on the cognition, very optimistic about ethnic tourism and high support for ethnic tourism. Although they give high support for ethnic tourism and show enthusiasm to tourists, they should be strengthened on their understanding and experience to negative effects of ethnic tourism development through education, publicity and other means and educated to fully understand influences of ethnic tourism and establish the concept of sustainable development of ethnic tourism.

The residents highly agree with positive effects of ethnic tourism and don't agree with the negative impact essentially. They keep positive attitudes toward the development of ethnic tourism and very satisfy with the present situation of ethnic tourism development, but their supports are very blind because of ignoring the negative impact of ethnic tourism the development.

They should be strengthened on not only their understanding and experience to negative effects of ethnic tourism development through education, publicity and other means, but also participating ethnic tourism industry to experience the negative influences, especially to cognize ethnic culture transition , to sense the value of ethnic culture and form the awareness of sustainable development.

\section{Conclusions}

The stage of national tourism development determines the effect of host-guest interaction. In the process of national tourism development, with the development of host-guest interaction the understanding of the residents will become more and more mature, the awareness and cognition will be strengthened, of course and the attitudes toward tourism development will also be further divided. At present, the effect of host-guest interaction is not too bad. It is necessary to construct a sustainable development model of host-guest interaction among ethnic tourism sites, develop a positive attitude and realize the sustainable development of ethnic tourism destinations before there are no extreme attitudes.

\section{References}

[1] Zeng Yan, Wang Xia, li zhi.(2010).National tourist destination residents survey of tourism influence cognitive attitude. Journal of Yunnan Dianda , 93-96.

[2] Li Wei.(2005).National tourist destination cultural change and development. Beijing: National publishing house, $163 \sim 167,214$.

[3] Zhang Xiaoping.(2009).National tourism anthropology perspective. Yunnan university press, 247255.

[4] Wu Jiawei.(2010). Gender Stereotype in Tourism Host-guest Communication. Kehai Story Expo• Technology Exploration, (10):58.

[5] Lu Song. Lu Lin. WangLi. (2006). XiDi destination residents' environmental awareness study .Journal of Anhui normal university, 28 (2) : 230-233.

[6] Shen BaoJia. (2006).Theory of tourism destination social pressure problems. Travel journal, (3) : 48-51. 
[7] Wang Li, Lu Lin. (2006).Foreign tourist destination residents' perception and attitudes towards the impact of tourism research review and enlightenment. Travel journal, 20 (3) : 87-93

[8] Lu Chuntian. Shi Jinglian. (2012).The development and update of reaserching on residents' cognitive and attitude in national tourist destination. Tourism Tribune (11) : 38-45

[9] Li Yanhua, Li Weihua, Yu Guangjian.(2010) A Study on the Interaction of Tourists in Ancient Cities Based on the Perspective of the Host: A Case Study of Pingyao Ancient City, Shanxi Province. Arid Zone Resources and Environment, (9):145-150.

[10] Lu Lu. (2011) Study on the interaction and mutual tolerance of main guests in ancient village tourist areas -- a case study of hongcun village in southern anhui province. Xi'an: Shaanxi Normal University Master Thesis:29-37.

[11] Sun Jiuxia.(2010) The Impact of Tourism on Ethnic Identity in the Destination Community: A Case Study Based on Different Tourism Roles. Journal of Sun Yat-sen University (Social Science Edition), 50(1):170-177. 